Advances in Geosciences, 4, 57-62, 2005

SRef-ID: $1680-7359 /$ adgeo/2005-4-57

European Geosciences Union

(c) 2005 Author(s). This work is licensed

under a Creative Commons License.

\title{
Lake and climate models linkage: a 3-D hydrodynamic contribution
}

\author{
L. F. Leon ${ }^{1,2}$, D. Lam ${ }^{3}$, W. Schertzer ${ }^{3}$, and D. Swayne ${ }^{2}$ \\ ${ }^{1}$ University of Waterloo, Waterloo, Ontario, N2G3L1, Canada \\ ${ }^{2}$ University of Guelph, Computing Research Laboratory for the Environment, Guelph, Ontario, N1G2W1, Canada \\ ${ }^{3}$ Environment Canada, National Water Research Institute, Burlington, Ontario, L7R4A6, Canada
}

Received: 1 August 2004 - Revised: 1 November 2004 - Accepted: 15 November 2004 - Published: 9 August 2005

\begin{abstract}
Under a Canadian Foundation for Climate and Atmospheric Sciences (CFCAS) project, targeted to study the feasibility to link regional climate models with lake models, one of the tasks was to consider such a coupling in large lakes. The objective is to provide detailed information on temperature and circulation distributions of the lake to take into account the spatial variability for temperature and the heat exchange through the water's surface. The major contribution of this work is focused on realistic representation of the heat fluxes and temperature distributions to and from lakes especially during the thermally stratified ice-free periods. This paper presents the detailed 3-D ELCOM model applied in Lake Erie in order to produce, at the surface layer of the lake, the spatial distribution of temperature and heat exchanges that eventually can be coupled with a regional climate model (CRCM). Preliminary results will be presented on how this lake model may improve the regional climate models, which currently do not consider such large lake circulation effects.
\end{abstract}

\section{Introduction}

Large lakes are recognized as an important agent which influences the circulation of the atmosphere; the atmospheric forcing also affects the lake thermal structure. This interaction is complex and continues to be a critical issue considering the millions of lakes in Canada, many of which are large, and are unaccounted for in current climatic models. Current models, without accounting for the water component, overestimate the heat transfers when forecasting in areas covered with lakes. The inclusion of a fully interactive coupling of a lake model with an atmospheric model for regional climate modeling is one option and an important objective of current Canadian Regional Climate Model (CRCM) development.

Correspondence to: L. F. Leon

(lfleonvi@uwaterloo.ca)
Only recently, has the CRCM implemented a lake model (Goyette et al., 2000) as an initial attempt to simulate the evolution of the water temperature and ice cover on the Laurentian Great Lakes. Another example is the implementation of a physicallybased column model which includes the effect of ice (Hostetler et al., 1993). These efforts so far pertain to simple one column (1-dimensional) and two layer (2dimensional) models. In thes e attempts for the CRCM, the lake is assumed to have uniform surface lake temperature. For small lakes, such assumption may be valid.

For large lakes such as the Laurentian Great Lakes, the lake surface temperature is not uniform and therefore requires a hydrodynamic model with finer spatial resolution architecture (Lam and Schertzer, 1999). Swayne et al. (2003) proposed to use a hierarchy of 1-D, 2-D and 3-D lake thermodynamic models depending on the size of the lake and available information to advance regional climate modelling. It aimed at conducting an independent evaluation of predictive capabilities of lake models for heat flux and thermal characteristics.

Such evaluations are a critical and essential element in the progression to development of fully coupled lake/CRCM model across lakes of different spatial scales. The purpose of our study is to evaluate the predictive capability of the 3-D models with the focus on large lakes in the context of linking them with the CRCM. The intention is to conduct an evaluation using high quality databases for selected large lakes in Canada, e.g. Lake Erie, Lake Ontario and Great Slave Lake, that have different morphometry over contrasting climatic regions. We will report on the preliminary results for Lake Erie as an example of how the 3-D model can be used to integrated with the CRCM.

\section{Technical challenges}

The idea of modeling lake-atmosphere interactions will require new research in: aggregating and distributing spatial quantities (e.g. how to fit a lake model into the CRCM grid 


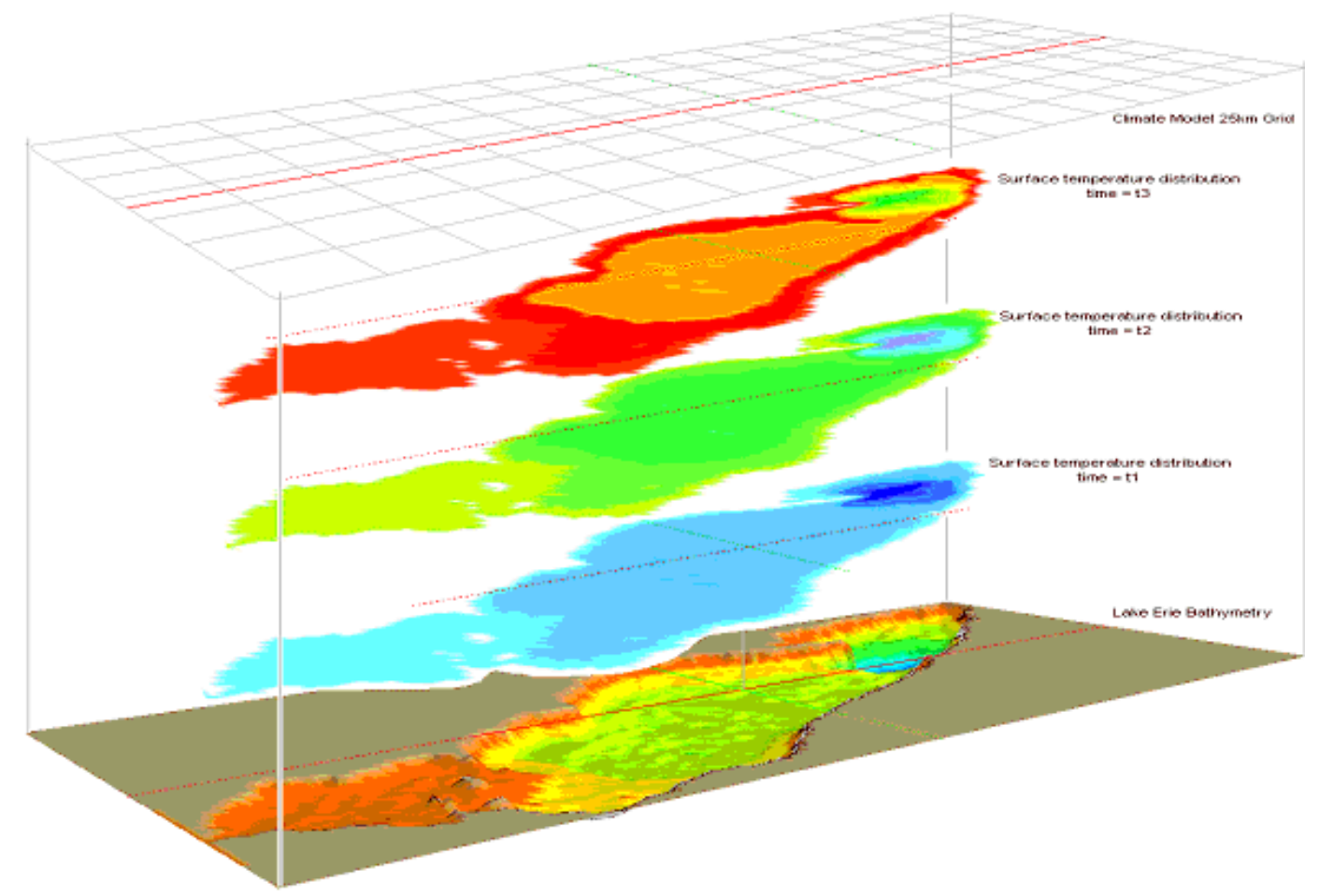

Fig. 1. Schematic representation of the proposed model coupling.

resolution); in synchronizing temporal scales (e.g. time steps of $15 \mathrm{~min}$ in CRCM vs. diurnal cycles produced by lake temperature models); and generalizing processes for application over lakes of different spatial scales. A major contribution of this work is focused on methodological procedures to evaluate heat fluxes and temperature distributions to and from lakes. Databases are required which are valid for model verification and uncertainty analyses. This study provides independent feed-back from lake modelers to CRCM modelers.

Such interaction is required to effect improvements in CRCM for application in the priority issues of climatic impacts research on aquatic ecosystems (e.g. on water quality, nutrient and dissolved oxygen concentrations). It also requires the lake modelers to adapt the model results required by the regional climate model, specifically the heat, mass and momentum exchanges at the air-water interface, surface air and water temperature, etc.

The main challenge is how to make these quantities consistent between the lake and the climate model. Two avenues of coupling will need to be explored. First the independent uncoupled simulations and the interactive coupling of the runs. In the first case, both models will run independently using the output of the other model as input for themselves. The second approach will require a linkage of input/output for each time step. Figure 1 represents the schematic of the proposed coupling and it shows different surface layers as simulated time progresses. The 3 -D results in a finer grid $(2 \times 2 \mathrm{~km})$ must be averaged at every time step for the larger grid resolution $(25 \times 25 \mathrm{~km})$ of the climate model (top schematic in Fig. 1).
A technical issue to resolve will be the coup ling of both models by exporting output data from the 3D hydrodynamic model to be used as input for the next time step in the climate model. Currently the bulk of the work is focused on attempting to couple these two models by emphasizing the consistency at the air-water interface, both in spatial and temporal resolution. Specifically, for heat transfer, the incoming and outgoing heat fluxes at the air-water interface should be the same at both models while the different time steps are set for a common value.

\section{Spatial distribution in lakes}

Canada contains several of the largest lakes in the world within the Laurentian Great Lakes (Lakes Superior, Michigan-Huron, Erie, Ontario), the Mackenzie Great Lakes. (Great Bear Lake, Great Slave Lake and Lake Athabasca) as well as others such as Lake Winnipeg. These lakes have large spatial extents, can have complicated bathymetric characteristics and can also have significant crosslake variability in meteorological and limnological components (Schertzer and Croley 1999). For example, Lake Erie is nearly 5-deg of latitude and 2-deg of longitude in size and has three distinct basins with maximum depths of $10 \mathrm{~m}$ (west basin), $25 \mathrm{~m}$ (central basin) and $64 \mathrm{~m}$ (east basin).

The heat transfer at the lake-atmosphere interface is influenced by such meteorological variables as air temperature, humidity, wind and solar radiation. The lake responds through both radiative and turbulent heat transfers and heating/cooling. Due to the high heat capacity of such large 

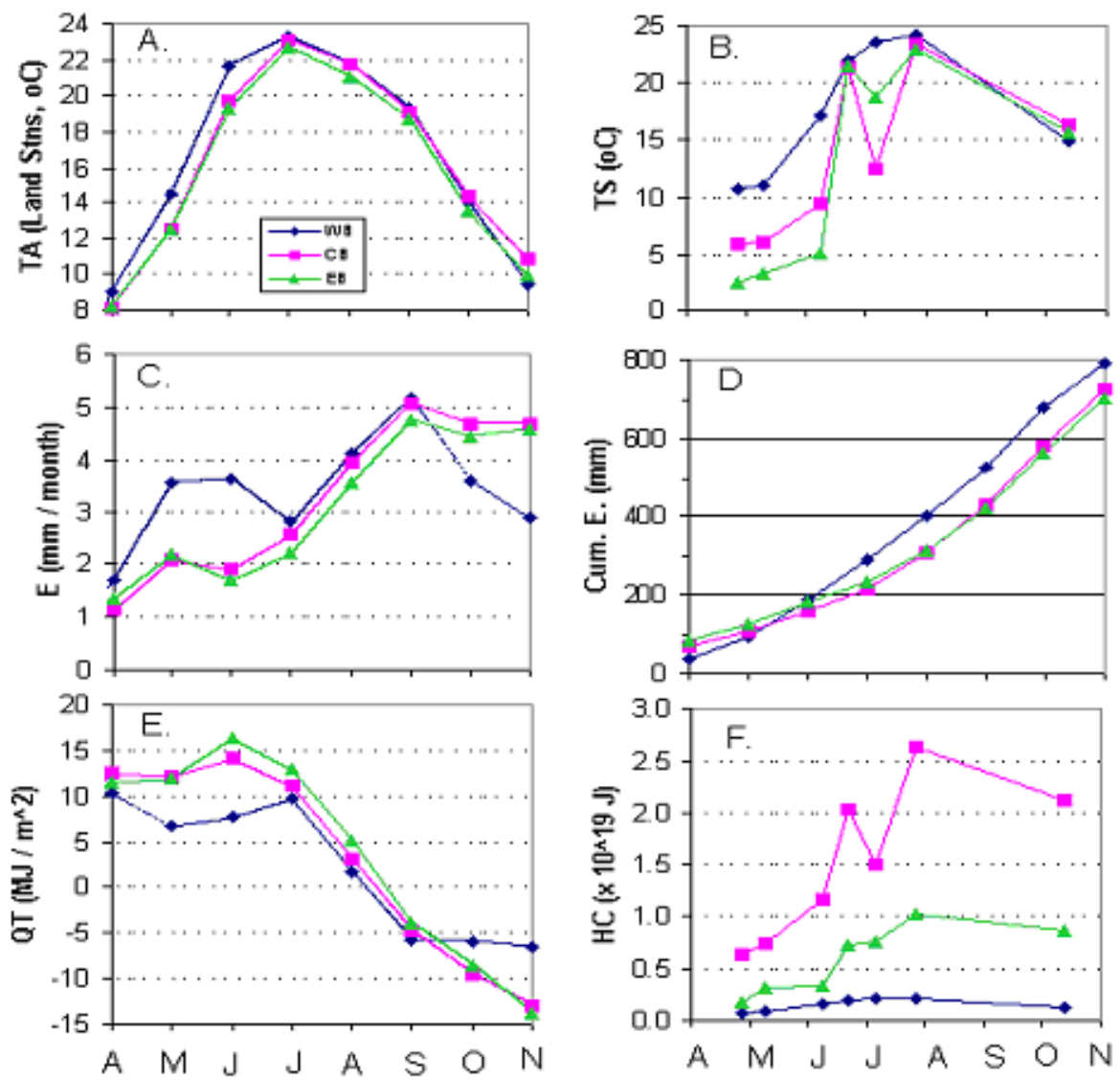

Fig. 2. Meteorological/Limnological data for west, central and east basin of Lake Erie (a) air temperature, (b) surface water temperature, (c) evaporation, (d) evaporation, (e) total heat flux, and (f) heat content.
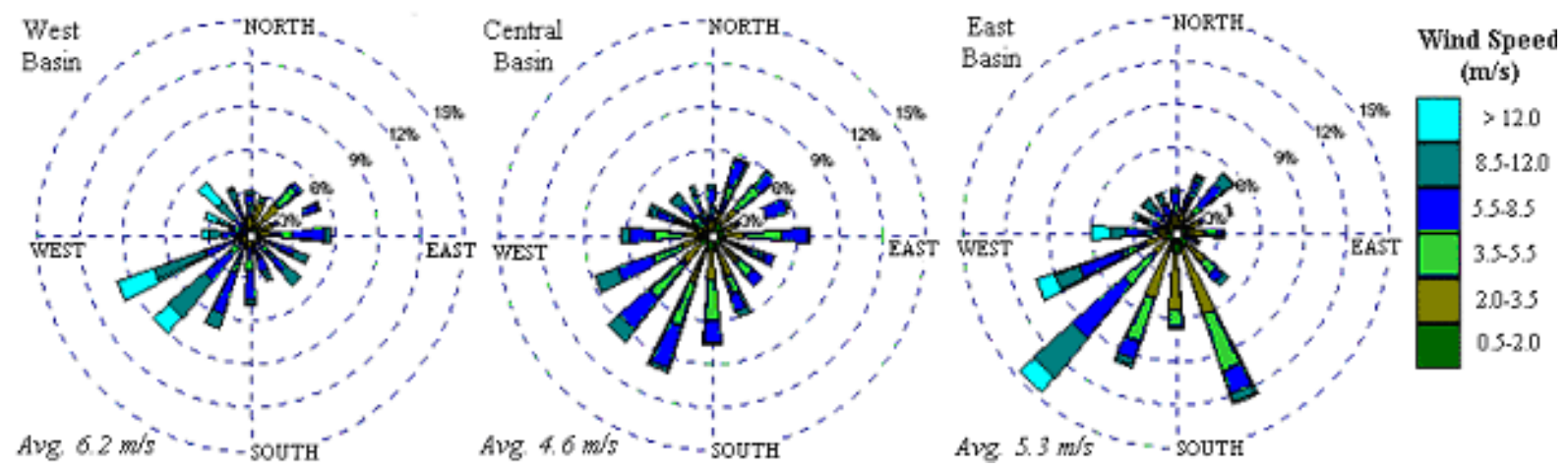

Fig. 3. Wind roses for the different basins in Lake Erie for 1994.

lakes, they can have a pronounced seasonal and regional influence as a result of seasonal lags in the heat transfers compared to the surround in land.

Figure $2 \mathrm{a}$ shows a pronounced difference between the mean monthly air temperatures recorded from land stations in the west basin of the lake compared to the other basins especially in the spring and again in the fall. The differences in air temperature and other meteorological variables during the spring warming phase combined with the shallow basin characteristics results in significant differences in the surface temperatures between basins (Fig. 2b).

In Lake Erie, the warmer conditions in the west basin during spring (Fig. 2c) results in significantly higher evaporation compared to the other basins. In fact, on large deep lakes such as Lake Erie and Great Slave Lake (Schertzer, 2003) condensation can occur in the cooler mid-lake while evaporation can be high in the warmer and shallow nearshore. 


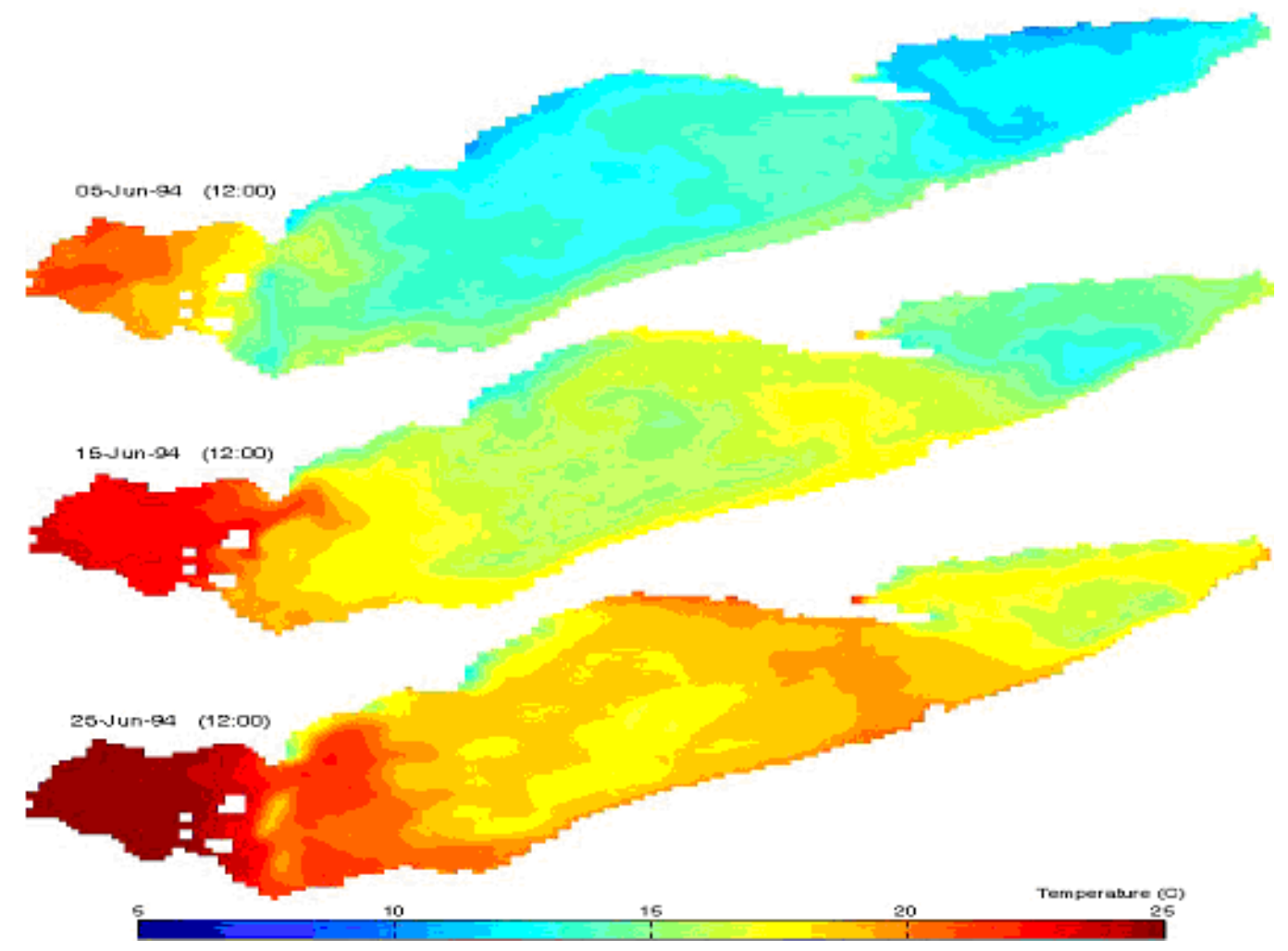

Fig. 4. Surface temperature in Lake Erie (3 time slices of the 1994 simulation).

Over the ice-free period, the large central basin in Lake Erie has the highest cumulative evaporation compared to either the west or east basins (Fig. 2d). The cross-lake differences in meteorological and lake response characteristics can be significant especially in the transition seasons. Because of the large spatial extents of such lakes, a 3-dimensional hydrodynamic model linked with a 3-dimensional atmospheric model is critical for realistic simulation of the influence of these lakes within the regional climate model.

Figure 3 shows characteristics of the wind field across the lake. As can be seen from the wind roses, the dominant wind direction is from the SW in all three basins, and the average wind speed is in the order of $5 \mathrm{~m} / \mathrm{s}$. The combined differences in air temperature, surface water temperature and wind influences the total radiative and turbulent heat exchange (Fig. 2e), the vertical temperature structure and lake heat content (Fig. 2f) (Schertzer et al., 1987). On a lake-wide basis, the latent heat flux is often a dominant component compared to other turbulent exchanges, generally small in the spring but high in the fall the lake heat content is released to the atmosphere.

\section{The 3-D model}

During the last decade a series of three-dimensional hydrodynamic models have been developed at different research institutes. An overview can be found in Lynch and Davies (1995) which includes the well known Princeton Ocean
Model (Blumberg and Mellor, 1987; Schwab and Bedford, 1994; Simons, 1975). The model used in this application is ELCOM (Estuary and Lake COmputer Model). ELCOM is a three-dimensional hydrodynamics model for lakes and reservoirs, and is used to predict the variation of water temperature and salinity in space and time (Hodges et al., 2000).

The heat exchange through the water's surface is governed by standard bulk transfer models found in the literature (Schertzer et al., 1987). Energy transfer across the free surface is separated into nonpenetrative components of long-wave radiation, sensible heat transfer, and evaporative heat loss, complemented by penetrative short-wave radiation. Non-penetrative effects are introduced as sources of temperature in the surface-mixed layer, whereas penetrative effects are introduced as source terms in one or more grid layers on the basis of an exponential decay and an extinction coefficient.

ELCOM computes a model time step in a staged approach consisting of introduction of surface heating/cooling in the surface layer. The solution grid uses rectangular Cartesian cells with fixed Dx and Dy (horizontal) grid spacing, whereas the vertical Dz spacing may vary as a function of $z$ but is horizontally uniform. The solution is based in the Arakawa $\mathrm{C}$-grid stencil where velocities are defined on cell faces with the free-surface height and scalar values on cell centers. The free-surface height in each column of grid cells moves vertically through grid layers as required by the free-surface evolution equation. To be confident enough with the results 


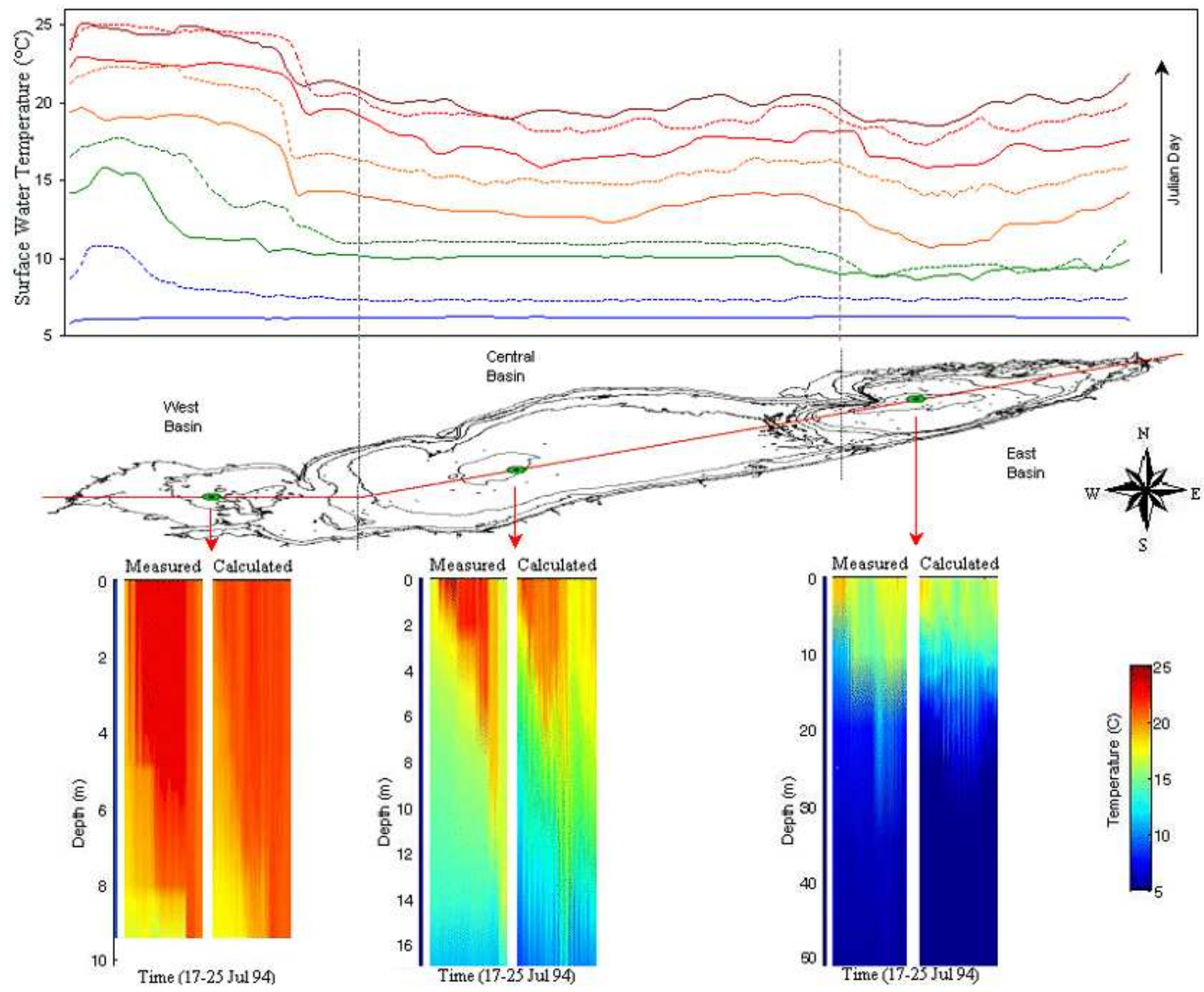

Fig. 5. Temperature results of the 3-D model. Top: surface temperature gradient on the lake Bottom: profiles for a selected week in 1994 (extracted from Leon et al., 2004).

of the 3-D model, several field data for 1994 were used to validate the hydrodynamics on the lake (Leon et al., 2004). To demonstrate the importance of the spatial distribution on Lake Erie, Fig. 4 presents the model output for surface temperature during the warming period of the 1994 simulation.

Figure 5 is an extract of such results showing the surface temperature gradient from west to east and selected profile comparisons of measured and calculated values at three lake sites. As can be seen from Fig. 5, the spatial distribution of temperature in such a great lake as Lake Erie, is quite important (temperature differences between west and east up to $8^{\circ} \mathrm{C}$ ). The $\mathrm{CRCM}$ has a grid resolution of $25 \mathrm{~km}$, then for day 215 , the average temperature to pass to the climate model are in the order $25^{\circ} \mathrm{C}, 20^{\circ} \mathrm{C}$ and $18^{\circ} \mathrm{C}$ for the west, central and east basins. For the coupling, distributions of temperature, evaporation and heat fluxes can be computed directly from the 3-D model results at any time step. The results so far indicated that we achieved internal consistency in the lake model in that the west-east gradient of surface temperature gradient is consistent with the heat content (Fig. 3) and with the internal thermal structure as depicted in Fig. 5.
These results, however, were obtained with measured air temperature, wind and heat fluxes. The next challenge will be to resolve the issue of coupling both models by exporting output data from one model (i.e. 3-D hydrodynamics) to be used as input for the next time step in the other model (CRCM), and vice versa, without the assistance of measurements. Currently we are attempting to couple these two models by emphasizing the consistency at the air-water interface. Specifically, for heat transfer, the incoming and outgoing heat fluxes at the air-water interface should be the same at both models. In this case, the fluxes from the CRCM will be used as input to the lake model and new updated fluxes are fed back from the lake model to the CCRM. Some iterations may be required if necessary. Similarly, the mass transfer is made consistent via the evaporation mechanism for water loss from the lake and via precipitation for water gain at the air-water interface. For momentum transfer, the wind stress should be made consistent in both models. 


\section{Conclusions}

We have successfully applied a 3-D hydrodynamic model to Lake Erie. The next step will be to directly connect the 3-D results with the CRCM model with its selected grid resolution and time step. This will have the advantage of seamlessly rendering the air and water models in tandem in both spatial and temporal steps and thereby achieving comparable numerical stability and accuracy, as well as generating detailed information on temperature and circulation distributions of the lake. However, it is also recognized that the 3-D approach currently has a disadvantage of high computational cost and requires detailed input data, not to mention the difficulty of having sufficient data for model calibration and verification. Thus, we propose that the current generation of the 3-D hydrodynamic model will be limited to only a few of the larger lakes lakes such as Laurentian Great Lakes and others such as Great Slave Lake in Canada for this study.

Acknowledgements. The authors wish to thank the support from Canadian Foundation for Climate and Atmospheric Sciences, the Natural Sciences and Engineering Research Council of Canada, and Environment Canada. We thank the support and discussion with M. McKay at the Meteorological Service of Canada, W. Rouse from McMaster University and Rene Laprise from the Universite du Québec á Montréal. Also acknowledged is the support from R. Smith at the University of Waterloo and the support of J. Imberger at the University of Western Australia for the use of the ELCOM model.

Edited by: P. Krause, S. Kralisch, and W. Flügel

Reviewed by: anonymous referees

\section{References}

Blumberg A. and Mellor, G.: A description of a three-dimensional coastal ocean circulation model, In Three-Dimensional Coastal Ocean Models, 1-16, AGU, Washington D.C., 1987.

Goyette, S., McFarlane, N., and Flato, G.: Application of the CRCM to the Laurentian Great Lakes Region: Implementation of a Lake Model, Atmos.-Ocean, 38, 481-503, 2000.
Hodges, B. R., Imberger, J., Saggio, A., and Winters, K. B.: Modeling basin-scale internal waves in a stratified lake, Limnol. Oceanogr., 45 (7), 1603-1620, 2000.

Hostetler, S. W., Bates, G. T., and Giorgi, F.: Interactive coupling of a lake thermal model with a regional climate model, J. Geophys. Res., 98, 5045-5057, 1993.

Lam, D. C. L. and Schertzer, W. M.: Potential Climate Change Effects on Great Lakes Hydrodynamics and Water Quality, American Society of Civil Engineers (ASCE) Press, Reston, Virginia, 232 p., 1999.

León, L. F., Imberger, J., Smith, R. E. H., Hecky, R. E., Lam, D. C. L., and Schertzer, W. M.: Modeling as a Tool for Nutrient Management in Lake Erie: A Hydrodynamics Study, J. Great Lakes Res., Lake Erie Trophic Status Special Issue, in press, 2004.

Lynch, D. R. and Davies, A. M.: Assessment for Coastal Ocean Models, Coastal and Estuarine Studies, Vol. 47, American Geophysical Union, 1995.

Schertzer, W. M. and Croley II, T. E.: Climate and Lake Responses, Chapter 2, p. 1-74, in: Potential Climate Change Effects on Great Lakes Hydrodynamics and Water Quality, edited by: Lam, D. C. L., ASCE Press, Reston, Virginia, USA, 232 p. 1999.

Schertzer, W. M., Saylor, J. H., Boyce, F. M., Robertson, D. G., and Rosa, F.: Seasonal thermal cycle of Lake Erie, J. Great Lakes Res. 13 (4), 468-486, 1987.

Schertzer, W. M., Rouse, W. R., Blanken, P. D., and Walker, A. E.: Over-lake meteorology and estimated bulk heat exchange of Great Slave Lake in 1998-99, J. Hydrometeor., 4, 649-659, 2003.

Schwab, D. J. and Bedford, K. W.: Initial implementation of the Great Lakes Forecasting System: a real-time system for predicting lake circulation and thermal structure, Water Poll. Res. J. Canada, 29, 203-220, 1994.

Simons, T. J.: Verification of numerical models of Lake Ontario: Part II: stratified circulation and temperature changes, J. Phys. Oceanogr., 5, 98-110, 1975.

Swayne D. A., Lam D. C. L., Mackay, M., Rouse, W., and Schertzer, W. M.: Preliminary Assessment of the Interaction Between the Canadian Regional Climate Model and Lake ThermalHydrodynamic Models, Proc. 5th International Symposium on Environmental Software Systems (ISESS 03), 27-30 May 2003, Austria, IFIP Conference, ISBN 3-901882-16-2, pp. 161-177, 2003. 